\title{
Ruptured Middle Cerebral Artery Aneurysms: A Single-Center Series Evaluating Microsurgical and Endovascular Treatment
}

\author{
MOHAMED AMER, M.D.; MOHAMED SHADAD, M.D. and ESSAM ABD EL-HAMEED, M.D.
}

The Department of Neurosurgery, Faculty of Medicine, Tanta University

\begin{abstract}
Background: Middle cerebral artery (MCA) represents $20 \%$ and is the $3 \mathrm{rd}$ most common location of intracranial aneurysms (IAs). MCA aneurysms are close to brain surface; this made surgical clipping the standard treatment for them. New advances in endovascular techniques and devices increased feasibility and safety of coiling of MCA aneurysms.
\end{abstract}

Aim of the Study: The aim of this study is to evaluate and compare feasibility, safety and outcome of surgical versus endovascular treatment of ruptured MCA aneurysms.

Patients and Methods: A retrospective study was done on 38 patients with ruptured MCA aneurysms who were treated between October 2013 and May 2017 at the Neurosurgery Department of Tanta University hospitals. They were divided into 2 groups: Surgical clipping (20 patients) and endovascular coiling (18 patients). Feasibility, complications and outcome were recorded and analyzed.

Results: The study included 38 patients with MCA aneurysms, 23 females and 15 males. The mean age was 53.5 years (20-67 years). Our microsurgical cases included 20 patients presenting with SAH and good clinical condition, Hunt \& Hess score 1 and 2 in 60\%. At discharge, $16(80 \%)$ had good GOS and 4 (20\%) patients had poor GOS. After endovascular management of MCA aneurysms, all the 18 cases had favorable outcome (GOS grade 5\&4) which remained the same at the last follow-up. The rate of total MCA aneurysm occlusion in control angiogram performed after microvascular management was $100 \%$ and at the last follow-up was the same. The rate of total MCA aneurysm occlusion in control angiogram at the end of the endovascular procedure was $72 \%$, subtotal occlusion was achieved in 3 patients (17\%) and incomplete occlusion in another 2 patients $(11 \%)$.

Conclusion: Clipping and coiling for ruptured MCA aneurysms have comparable outcome. Microsurgery has less cost, good feasibility and more stability. Coiling has higher cost, better feasibility and less stability. However, patient selection is extremely important to optimize the outcomes.

Key Words: Rupture MCA - Surgical clipping - Endovascular coiling.

Correspondence to: Dr. Mohamed Amer, The Department of Neurosurgery, Faculty of Medicine, Tanta University

\section{Introduction}

MIDDLE cerebral artery (MCA) represents 20\% and is the 3 rd most common location of intracranial aneurysms (IAs). Ruptured MCA aneurysms are commonly associated with intracerebral hematomas, which are found in nearly $40 \%$ of cases. Rebleeding has a catastrophic morbidity in $48 \%$ to $78 \%$ [1]

There are two options for the management of ruptured MCA aneurysms: Endovascular coiling and open microsurgical clipping. The goal of aneurysm management is complete, durable obliteration without neurologic consequence. The position of the MCA in the sylvian fissure close to brain surface makes its surgical exposure straight forward while its complex angio-architecture challenges its navigation with the microcatheter. This rendered microsurgical clipping of MCA aneurysms is the standard management strategy for definitive obliteration of MCA aneurysms [2,3].

Surgical clipping is a more invasive procedure but also more durable. However, there are growing reports on safety, efficacy and feasibility of endovascular treatment as an alternative to microsurgery. Endovascular coiling has been used as the primary procedure for a wide spectrum of aneurysms. Patients prefer endovascular coiling over microsurgical clipping as the procedure seems safe, less invasive and cosmetically better [4-6]

After the appearance of the early results of the International Subarachnoid Aneurysm Trial (ISAT) group in 2002 suggesting superiority of coiling to clipping, a "coil first" policy has been widely adopted even for MCA aneurysms which were underrepresented in that study and also were the only aneurysm subgroup which showed better outcome after clipping than after coiling $[3,4,7]$. 
Although the early results of the Barrow Ruptured Aneurysm Trial (BRAT) were supportive to the "coil first" policy, the long-term follow-up results of both studies showed no significant difference in neurological outcome between coiling and clipping in addition to higher re-bleeding risk, re-treatment rate and lower obliteration rate in the coiling arm. Improved microsurgical technique and better case selection has led to better results in recent publications [1,8-10].

\section{Patients and Methods}

In this study, a retrospective analysis of 38 patients with ruptured MCA aneurysms who were treated between October 2013 and May 2017 at the Department of Neurosurgery of Tanta University Hospitals was done. They were divided into 2 groups retrospectively: Surgical clipping (20 patients) and endovascular coiling (18 patients). Feasibility, complications and outcome were recorded and analyzed.

All patients underwent clinical and routine laboratory investigations at presentation and preoperatively. Brain CT was done for all the patients for the presence of $\mathrm{SAH}, \mathrm{ICH}$, intraventricular blood and/or hydrocephalus. Angiography (computed tomographic angiography (CTA), magnetic resonance angiography (MRA) and/or conventional angiography) were done for all patients whether surgical or endovascular.

The choice of the preferred treatment strategy (clipping or coiling) for each patient was made by a discussion of our team of microsurgery and endovascular surgery and was based on the following several factors: Aneurysm (size, morphology, dome to neck ratio), microsurgical anatomy (parent artery, branch artery or perforator originating from the neck), patient (preference, clinical status, medical co-morbidity) and presence or absence of intracerebral hematoma or hydrocephalus.

After clinical assessment, initial CTA, MRA or conventional cerebral angiography were done and after discussing the two option of management with the patient relatives and written consent, we proceed to definitive treatment. Patients with a good Hunt \& Hess grade $(1 \& 2)$ were treated within 72 hours after the SAH. The treatment was postponed in a few patients because of late referral or late decision of the patient relatives or co-morbidity. Patients in a poor clinical condition (Hunt \& Hess 3-5) were admitted to the Neurosurgical ICU before the definitive treatment.

\section{Microsurgical technique:}

All aneurysms were operated using the lateral supraorbital (LSO) or the pterional approach according to personal experience. Because we are operating on ruptured aneurysms, we always expect oozing edematous brain and fear from aneurysm re-rupture. Thus, we take more time to have a lax brain and more CSF needs to be released. We usually go to the lamina terminalis and remove CSF directly from the third ventricle. Then we go for proximal control before any manipulation at the aneurysm. We perform sharp dissection of the aneurysm under high magnification and bipolar shaping of the aneurysm neck can be done under temporary clipping when needed.

Now final clipping and checking vessel patency can be done. After securing the aneurysm, removal of remaining ICH can be completed. We sometimes leave a small blood clot to avoid injury of lenticulostriate perforators. CT brain scan was done postoperatively to follow the hemorrhage, ventricular size, related infarctions or other findings. Angiographic follow-up was done on the second postoperative day to detect complete aneurysm closure, patency of parent vessels and any vasospasm. It is then at 3 months, 6 months and/or at 1 year to detect recurrence or complication.

\section{Endovascular Technique (EVT):}

All patients received general anesthesia. No systemic anticoagulation with heparin was administered. Heparin was only added to flushing solutions (2500 IU heparin $/ 1000 \mathrm{ml} 0.9 \%$ saline) of guiding catheter and microcatheter during the procedure. Activated clotting time was kept 2-3 folds of the normal value. The standard transfemoral approach with double wall puncture was used in all patients. With the aid of high-resolution digital biplane fluoroscopy and road-mapping, using 5French (F) diagnostic catheter (Bern, Boston scientific), initial cerebral angiography was performed to define the optimal projection for definition of the aneurysmal neck and its relationship to the parent artery and adjacent arterial branches.

Exchange of 5-F diagnostic catheter by 6-F guiding catheter (Guider soft tip; Stryker) was performed using long exchange wire. 7-F guiding catheter (Envoy; Cordis Neurovascular) used only with balloon remodeling technique. The guiding catheter was placed in the appropriate position in the cervical carotid. The microcatheter (Excelsior SL-10; Stryker or Echelon; Covidien) was shaped by steam and placed coaxially through guiding catheter and navigated into the aneurysm with the 
aid of a 0.010 or 0.014 inch guide microwire (Transend; Stryker or Traxcess; Microvention).

Different varieties of coils are now available with different methods of detachment (electrical, thermal and mechanical); sizes (10 or-18); shapes $(360,3 \mathrm{D}, 2 \mathrm{D})$, and consistency (standard, soft, and ultra-soft). Stretch resistance (SR) technology was added. Choice between different types of coils were done according to size and status (either ruptured or unruptured) of the treated aneurysms. Aneurysm coiling start with framing followed by filling and finally finishing with different types of coils till achieving total opacification of the aneurysm lumen.
Angiographic outcome at final control angiogram was evaluated according to Raymond classification including total, subtotal and incomplete obliteration. MRI/MRA angiographic follow-up was performed in all patients before discharge. Second MRI/MRA (DSA in selected cases) was obtained after 3-12 months according to patient presentation and angiographic outcome at hospital discharge. The changes on follow up in comparison with the immediate post treatment angiogram or latest follow up is classified into; stable occlusion, further thrombosis, and recanalization. Clinical evaluation at hospital discharge was performed with Glasgow Outcome Scale (GOS).

Selected cases:

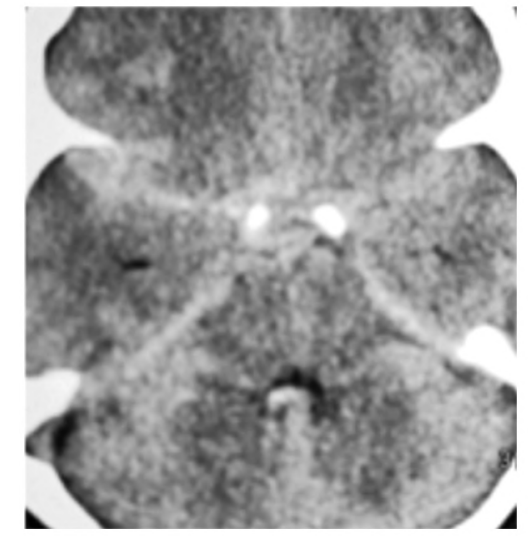

(A)

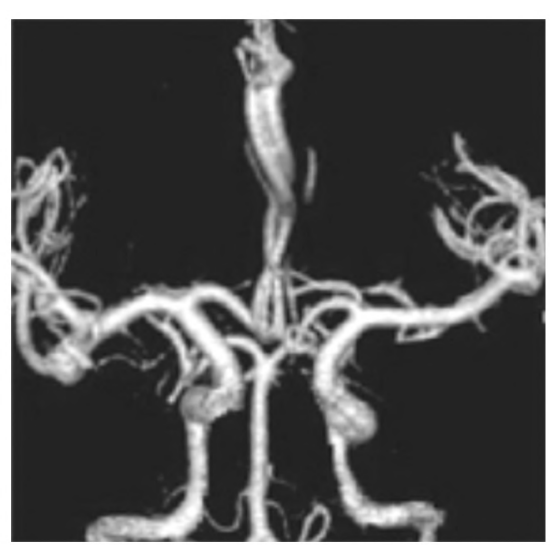

(B)

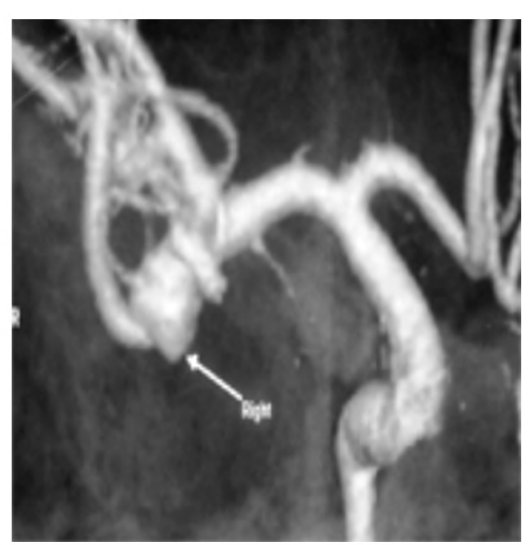

(C)

Fig. (1): Female patient 55 years old presented with headache and disturbed conscious level (H\&H grade III). Preoperative CT brain shows SAH filling rt. Sylvain fissure \& Preoperative CTA images 3D reconstruction show Rt. MCA bifurcation aneurysm.

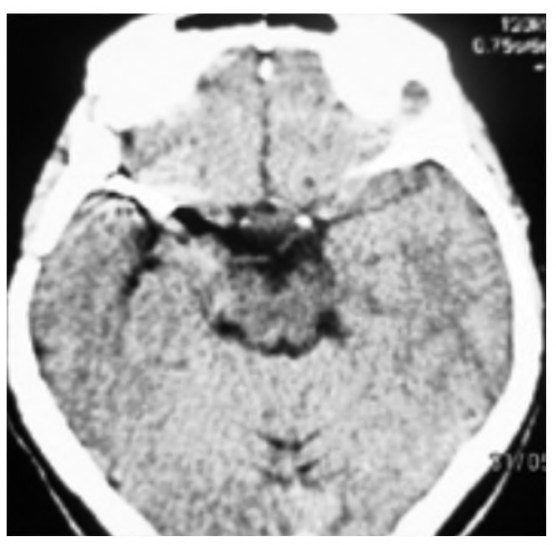

(A)

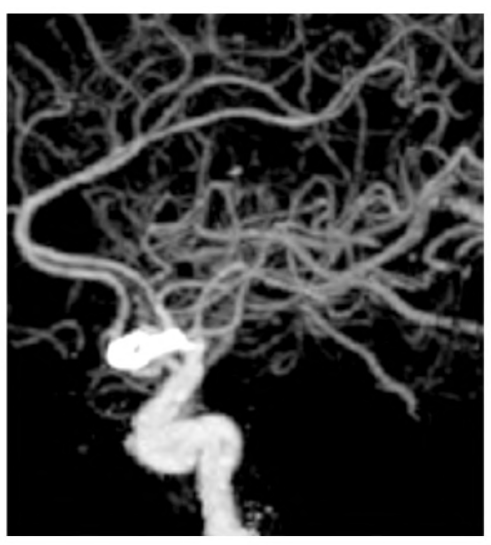

(B)

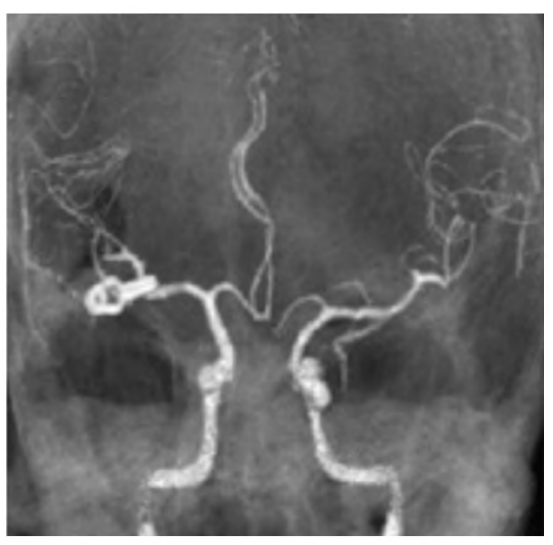

(C)

Fig. (2): Postoperative CT image shows Rt. pterional craniotomy \& successful clipping. Postoperative CTA 3D reconstruction sagittal image shows complete aneurysm occlusion. 


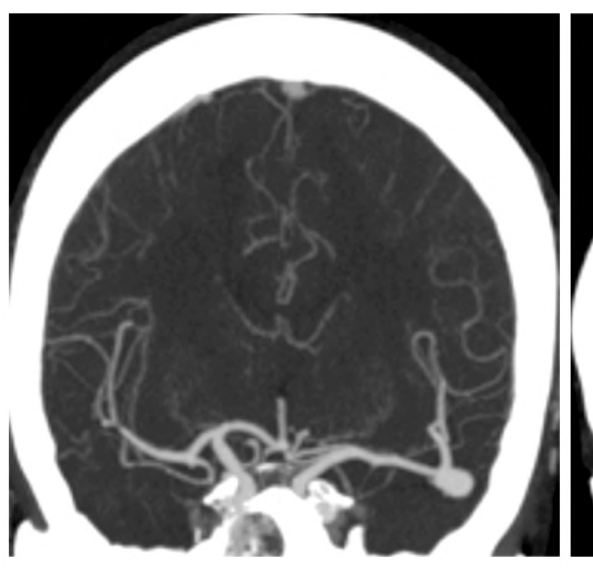

(A)

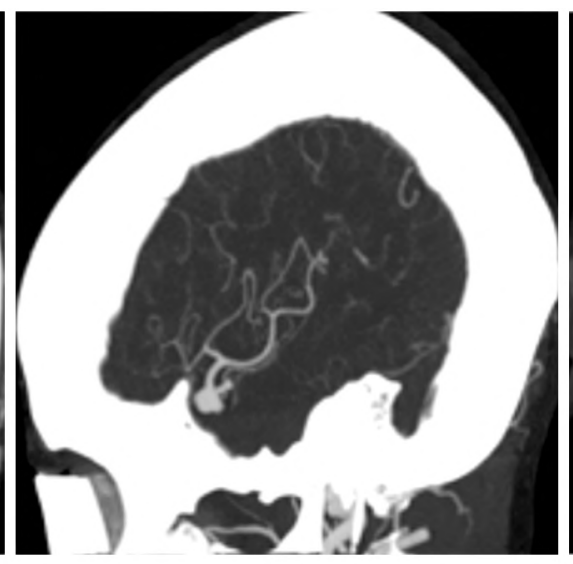

(B)

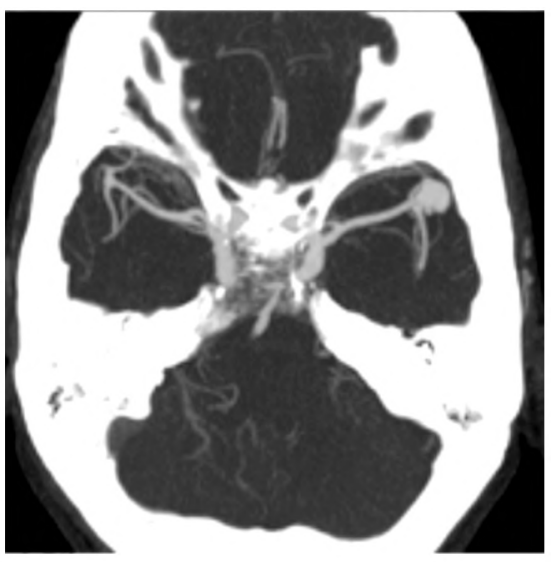

(C)

Fig. (3): Female patient 35 years old presented with headache and disturbed conscious level (H\&H grade II). Preoperative CTA reconstructed coronal, axial and sagittal images show Lt. MCA bifurcation aneurysm.

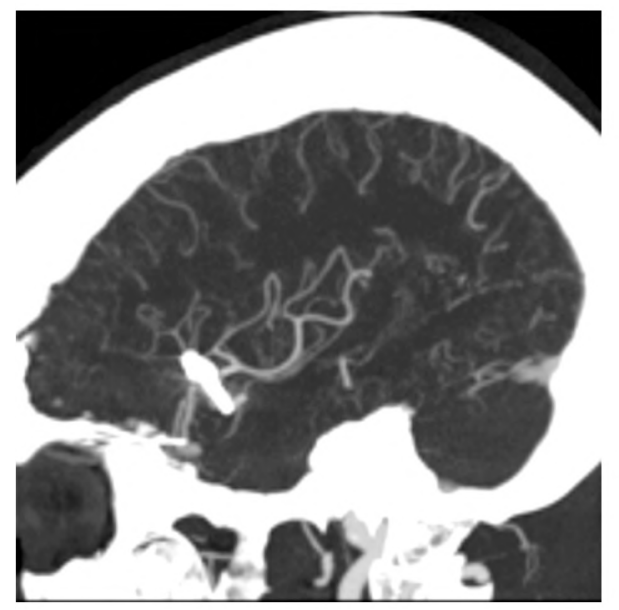

(A)

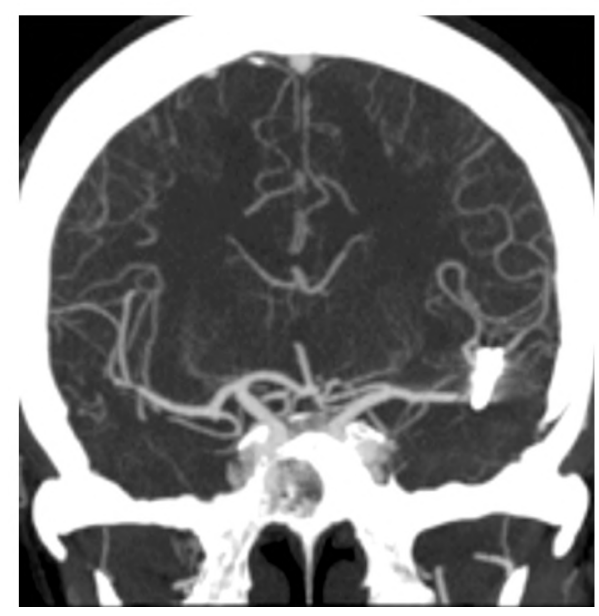

(C)

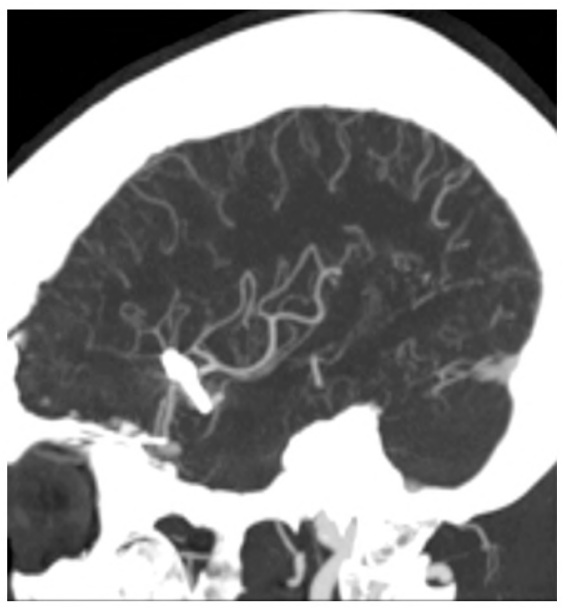

(B)

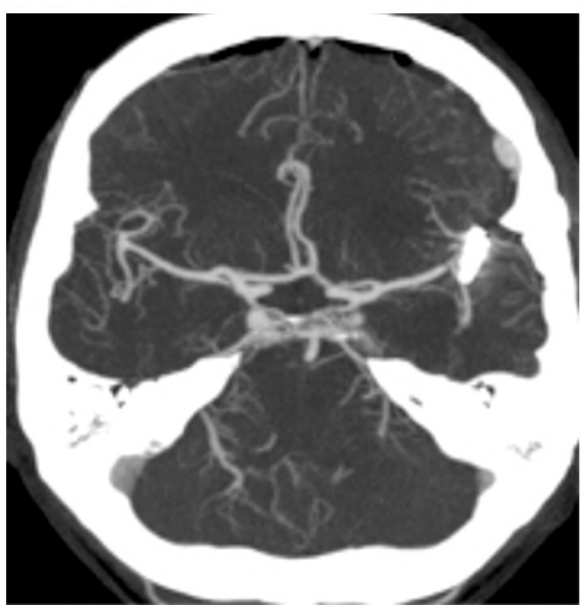

(D)

Fig. (4): Postoperative CT images show Lt. Pterional craniotomy \& successful clipping. 

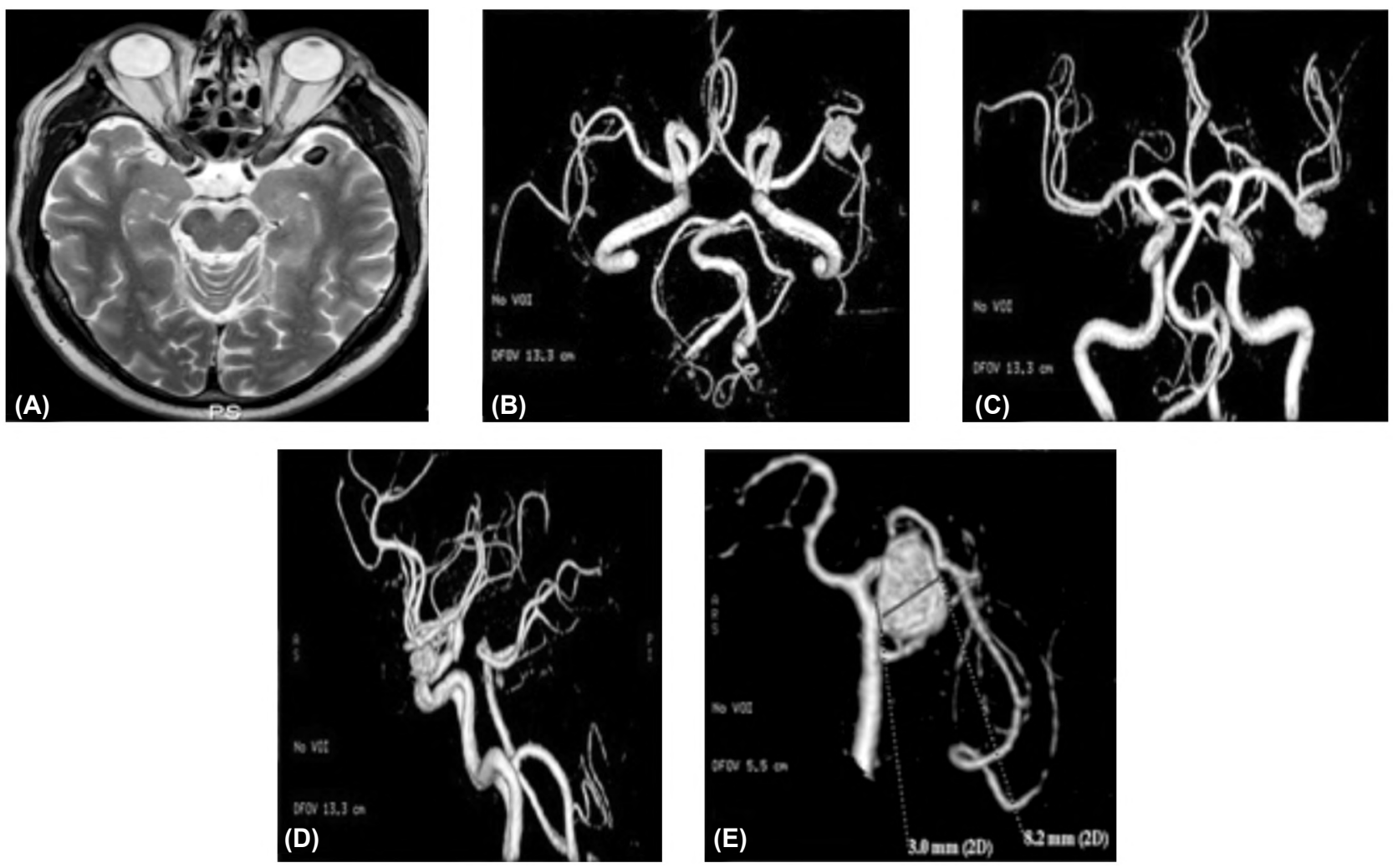

Fig. (5): Female patient 45 years old presented with SAH (H\&H grade II). Preoperative MRI \& CTA images show LT MCA bifurcation aneurysm.
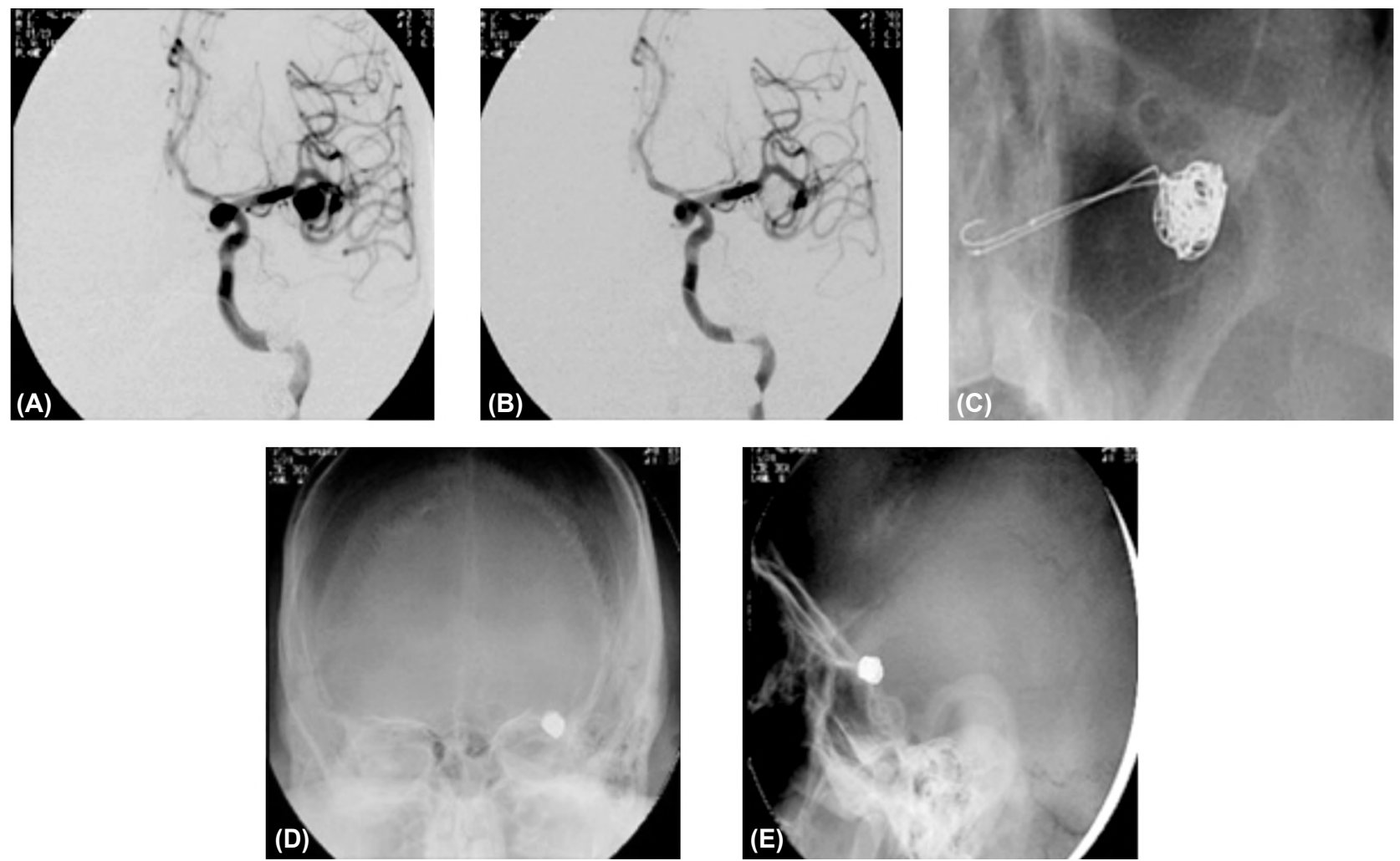

Fig. (6): Endovascular coiling with double microcatheter technique with total occlusion of aneurysm at final control DSA. 

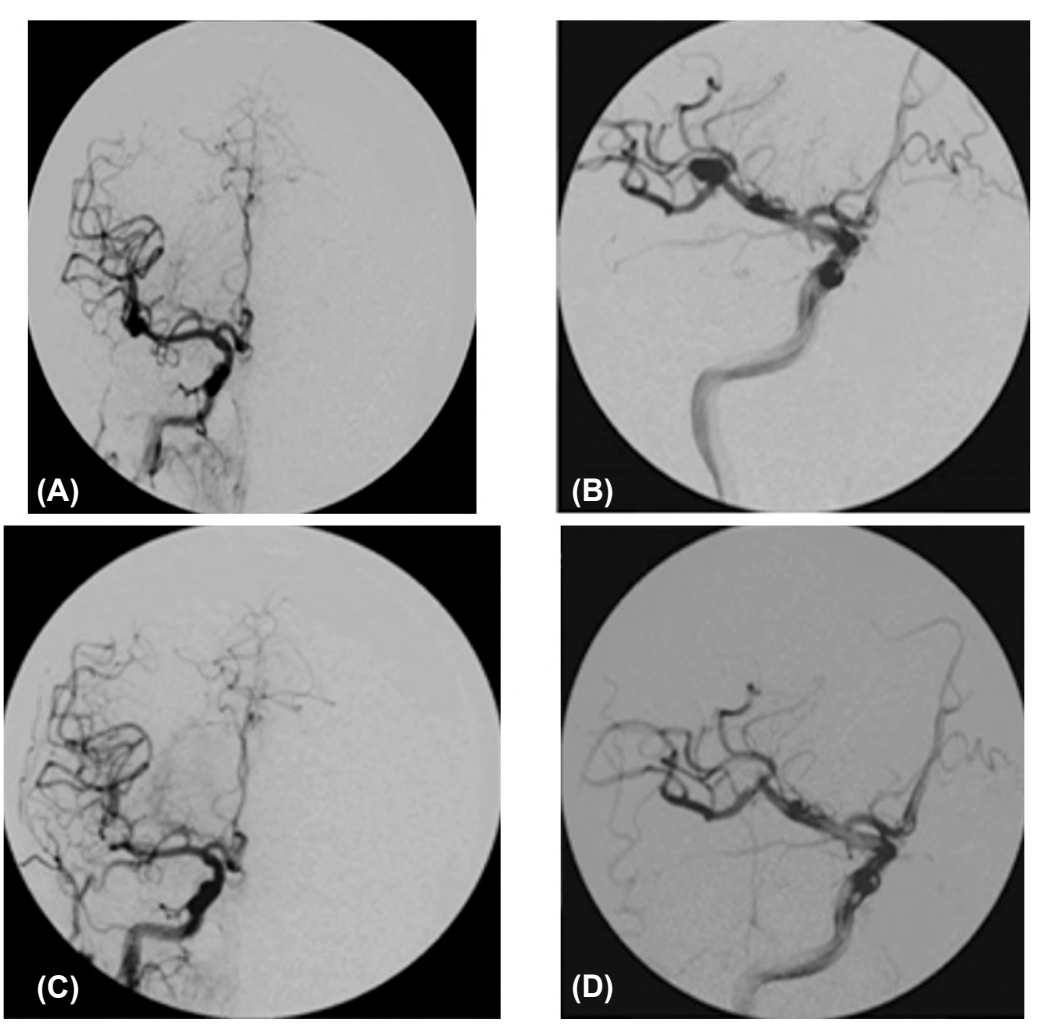

Fig. (7): Male patient aged 46 years and presented with SAH (H\&H grade I). DSA showing wide neck RT MCA bifurcation aneurysm with total occlusion at final control DSA.

\section{Results}

In this study, 38 patients with ruptured MCA aneurysms were treated at the Department of Neurosurgery, Tanta University Hospitals between October 2013 and May 2017. Twenty three patients were females $(60.5 \%)$ and $15(39.5 \%)$ were males. The mean age was 54 years (20-67 years).

\section{Microsurgical group:}

It included 13 females and 7 males, with a mean age of 53 years (35-67 years). Seven patients were smokers and 10 had hypertension. Twenty MCA aneurysms and 6 aneurysms outside the MCA were secured. The anterior communicating artery (ACOM) was the most frequent associated location for aneurysms diagnosed with MCA aneurysms. Of the 20 cases with ruptured MCA aneurysms, 8 patients had intracerebral hematoma. Hunt and Hess grade I and II at admission was recorded in $60 \%$ of the patients Table (1).

The majority of aneurysms (95\%) were at MCA bifurcation or M1 segment aneurysms. Most of the aneurysms $(80 \%)$ were smaller than $10 \mathrm{~mm}$. The aneurysm characteristics are illustrated in Tables $(2,3)$. Microsurgical treatment of MCA aneurysms was straightforward in most cases where it was simple clipping for 18 aneurysms and just bipolar coagulation for two aneurysms. The most frequent procedural complication was intraoperative rupture during dissection in 4 cases.

The rate of total MCA aneurysms occlusion after microsurgery was $100 \%$ Tables $(4,5)$. Microsurgical clipping was done in cases with large ICH and in cases with morbid clinical condition. Clinical evaluation at hospital discharge was performed with Glasgow Outcome Scale (GOS). Good clinical outcome (grade 5) was achieved in 16 cases $(80 \%)$ of patients after microsurgery, disability (grade 3 ) in one case while 3 cases (grade 1) died from vasospasm Table (6).

\section{Endovascular group:}

It included 10 females and 8 males, with a mean age of 54 years (20-65 years). Risk factors included cigarette smoking in 8 patients, hypertension in 6 patients. One patient had ACOM aneurysm. Initial clinical grading was performed according to Hunt and Hess scale. Of 18 patients with SAH, 2 patients had grade I, 12 patients had grade II, 4 patients had grade III, and none of patients had grade IV or $\mathrm{V}$ as in Table (1).

Majority of case in endovascular group were MCA bifurcation aneurysm in 15 patients $(83 \%)$, M1 segment in 2 patients (11\%) and M2 segment in 1 patient $(6 \%)$ Table (2). 
Regarding the size of the aneurysms, 14 were small $(>10 \mathrm{~mm}), 4$ were large $(11-24 \mathrm{~mm})$, and none were giant aneurysms (25mm or more) Table (3). The size of the aneurysm neck was small (less than $4 \mathrm{~mm}$ ) in 14 aneurysms and wide neck (more than $4 \mathrm{~mm}$ ) in 4 aneurysms. Neck to dome ratio was favorable in 14 aneurysms (more than 2) and unfavorable (less than 2) in 4 aneurysms but none of patients had ratio less than 1 .

Standard single microcatheter technique used in 12 cases $(67 \%)$, double microcatheter technique in 4 cases $(22 \%)$ and balloon remodeling technique in 2 cases (11\%). Procedural complication include thrombosis of Rolandic artery and immediate recanalization achieved with injection of Aggrestate and one perforation with minor leakage of the dye near the end of coiling and stopped with adding more coils.

Total occlusion achieved in 13 cases (72\%), subtotal occlusion with small neck remnants achieved in 3 cases (17\%) and incomplete occlusion in 2 cases (11\%) Table (4).

Angiographic follow-up revealed stable occlusion in $15(83 \%)$, recanalization in 2 patients $(11 \%)$ and further occlusion in one patient with incomplete occlusion (6\%) Table (5).One of the 2 patients with recanalization underwent second session and more coils added and other patient under more follow-up. At hospital discharge 16 patients (89\%) had good clinical outcome (grade 5) and 2 patients had minor deficits (GOS grade 4) Table (6).

Table (1): Shows Hunt \& Hess grade in our cases.

\begin{tabular}{|c|c|c|c|c|}
\hline \multirow[t]{2}{*}{ Grade } & \multicolumn{2}{|c|}{$\begin{array}{l}\text { Number } \\
\text { of patients Percentage }\end{array}$} & $\begin{array}{l}\text { Number } \\
\text { of patients }\end{array}$ & Percentage \\
\hline & \multicolumn{2}{|c|}{ Microsurgical cases } & \multicolumn{2}{|c|}{ Endovascular cases } \\
\hline Grade I & 5 patients & 25 & 2 patients & 11.1 \\
\hline Grade II & 7 patients & 35 & 12 patients & 66.7 \\
\hline Grade III & 3 patients & 15 & 4 patients & 22.2 \\
\hline Grade IV & 3 patients & 15 & 0 & 0 \\
\hline Grade V & 2 patients & 10 & 0 & 0 \\
\hline
\end{tabular}

Table (2): Shows MCA aneurysm location.

\begin{tabular}{llclc}
\hline $\begin{array}{l}\text { Aneurysm } \\
\text { Location }\end{array}$ & of patients & Percentage & $\begin{array}{c}\text { Number } \\
\text { of patients }\end{array}$ & Percentage \\
\hline & Microsurgical cases & \multicolumn{2}{l}{ Endovascular cases } \\
M1 & 2 patients & 10 & 2 patients & 11.1 \\
M1/M2 & 17 patients & 85 & 15 patients & 83.3 \\
M2/M3 & 0 & 5 & 1 patients & 5.6 \\
\hline
\end{tabular}

Table (3): Shows MCA aneurysm size.

\begin{tabular}{|c|c|c|c|c|}
\hline $\begin{array}{l}\text { Aneurysm } \\
\text { Size }\end{array}$ & \multicolumn{2}{|c|}{$\begin{array}{l}\text { Number Percentage } \\
\text { of patients }\end{array}$} & $\begin{array}{l}\text { Number } \\
\text { of patients }\end{array}$ & Percentage \\
\hline & \multicolumn{2}{|c|}{ Microsurgical cases } & \multicolumn{2}{|c|}{ Endovascular cases } \\
\hline$>10 \mathrm{~mm}$ & 16 patients & 80 & 14 patients & 77.8 \\
\hline $10-24 \mathrm{~mm}$ & 4 patients & 20 & 4 patients & 22.2 \\
\hline $25 \mathrm{~mm}$ or $<$ & 0 & 0 & 0 & 0 \\
\hline
\end{tabular}

Table (4): Shows degree of occlusion.

\begin{tabular}{|c|c|c|c|c|}
\hline $\begin{array}{l}\text { Degree of } \\
\text { occlusion }\end{array}$ & \multicolumn{2}{|c|}{$\begin{array}{l}\text { No. of } \\
\text { patients }\end{array}$} & $\begin{array}{c}\text { No. of } \\
\text { patients }\end{array}$ & Percentage \\
\hline & \multicolumn{2}{|c|}{ Microsurgical cases } & \multicolumn{2}{|c|}{ Endovascular cases } \\
\hline Total & 20 patients & 100 & 13 patients & 72.2 \\
\hline Subtotal & 0 & 0 & 3 patients & 16.7 \\
\hline Incomplete & 0 & 0 & 2 patients & 11.1 \\
\hline
\end{tabular}

Table (5): Shows stability of occlusion on follow-up.

\begin{tabular}{lcccc}
\hline $\begin{array}{l}\text { Stability of } \\
\text { occlusion }\end{array}$ & \multicolumn{2}{c}{$\begin{array}{c}\text { Nofients Percentage } \\
\text { patients }\end{array}$} & $\begin{array}{c}\text { No of } \\
\text { pationtage }\end{array}$ \\
\hline \multicolumn{4}{c}{ Microsurgical cases } & \multicolumn{2}{c}{ Endovascular cases } \\
Stable & 20 patients & 100 & 15 patients & 83.3 \\
Recanalization 0 & 0 & 2 patients & 11.1 \\
$\begin{array}{l}\text { Further } \\
\text { occlusion }\end{array}$ & 0 & 0 & 1 patients & 5.6 \\
\hline
\end{tabular}

Table (6) Shows clinical outcome by Glasgow Outcome Scale.

\begin{tabular}{llccc}
\hline Grade & $\begin{array}{c}\text { No. of } \\
\text { patients }\end{array}$ & Percentage & $\begin{array}{c}\text { No. of } \\
\text { patients }\end{array}$ & Percentage \\
\hline & \multicolumn{2}{c}{ Microsurgical cases } & \multicolumn{2}{c}{ Endovascular cases } \\
Grade 5 & 16 patients & 80 & 16 patients & 88.9 \\
Grade 4 & 0 & 0 & 2 patients & 11.1 \\
Grade 3 & 1 patients & 5 & 0 & 0 \\
Grade 2 & 0 & 0 & 0 & 0 \\
Grade 1 & 3 patients & 15 & 0 & 0 \\
\hline
\end{tabular}

\section{Discussion}

Females represented $65 \%$ in our study population and most of the aneurysms (30 cases) were smaller than $10 \mathrm{~mm}$. MCA aneurysms usually arise from the MCA bifurcation or the proximal M1 segment. In this study, $95 \%$ of the aneurysms arose from either MCA bifurcation or M1 segment. Microsurgical clipping has been the standard strategy for complete obliteration of MCA aneurysms [5].

In our microsurgical cases, simple clipping of MCA aneurysms was sufficient to secure 18 cases of the 20 MCA aneurysms in whom attempted 
microsurgical clipping was done. Two small $(<5 \mathrm{~mm})$ MCA aneurysms were just coagulated with bipolar diathermy under temporary proximal control with a temporary clip then wrapped with crushed muscle and fibrin glue. When evaluating morbidity and mortality rates after surgical management of ruptured MCA aneurysms, it appears difficult to accurately estimate the morbidity and mortality related to the clipping procedure itself from the natural history of SAH [3,5]

Rodriguez-Hernandez et al., reported a large series of clipping of $632 \mathrm{MCA}$ aneurysms in 543 patients. The series included $282(51.9 \%)$ ruptured MCA aneurysms and 261 (48.1\%) unruptured MCA aneurysms. Complete occlusion was attained in $98.3 \%$ of cases. Poor outcome was reported in $29.8 \%$ of ruptured aneurysms. In our cases complete occlusion was attempted in $100 \%$ of cases and poor outcome was recorded in $20 \%$ of cases. This is similar to results of Van Dijk et al who had poor out-come in $20 \%$ of ruptured MCA aneurysms in their series of clipping of 151 consecutive MCA aneurysms [3,5]

Initially, it was noted that only a small percentage of MCA aneurysms were suitable for endovascular treatment, but improvement of endovascular techniques and the use of adjunctive devices as balloons and stents have markedly increased the feasibility and technical safety of endovascular treatment of MCA aneurysm. Keeping this in mind, we can better evaluate some recent series showing up to $98.8 \%$ feasibility of endovascular management of MCA aneurysms [3,11-13].

In our cases of ruptured MCA aneurysms, 8 patients presented with ICH causing mass effect. A rapid surgical intervention for hematoma evacuation and clipping of the ruptured MCA aneurysm was attempted in the same setting. In the literature, hematoma evacuation and securing the ruptured aneurysm in the same setting has been common policy in surgical series. This policy has been criticized as causing more intraoperative aneurysm rupture by de-tamponading the rupture site $[3,5,14]$

Some series of endovascular treatment of MCA aneurysms have advocated coiling of the ruptured aneurysm before surgical evacuation of the hematoma claiming that this approach protects against intraoperative aneurysm rupture. We consider the risks of this approach are much more than the presumed benefits as this will lead to delay in hematoma evacuation besides exposing the patients to hazards of both endovascular and surgical techniques [12,15]
The rate of total MCA aneurysm occlusion in control angiogram performed after microvascular management was $100 \%$ and at the last follow-up was the same. The rate of total MCA aneurysm occlusion in control angiogram at the end of the endovascular procedure was $72 \%$, subtotal occlusion was achieved in 3 patients (17\%) and incomplete occlusion in another 2 patients $(11 \%)$.

In the literature, the recurrence rate requiring re-treatment after endovascular management of MCA aneurysms is variable and ranges between $1.8 \%$ and $17.4 \%$. Mortimer et al., had $91.4 \%$ near occlusion rate and $4.3 \%$ re-treatment rate in their series of 300 MCA aneurysms. In the series of Jin et al., $17.5 \%$ of the $80 \mathrm{MCA}$ aneurysms that had follow-up were retreated. They reported young age, rupture status and wide neck to be predictors of recurrence $[12,16]$

When assessing patient-related features (age, gender, admission $\mathrm{H} \& \mathrm{H}$ grade, medical co-morbidity and special habits as smoking or alcohol consumption) with clinical outcome after microsurgery, univariate analysis showed that old age, medical co-morbidity and poor clinical conditions were the main patient-related factors associated with poor outcome. Multivariate analysis revealed that admission Hunt and Hess grade was the only statistically-significant patient-related feature ( $p=$ 0.04 ) affecting clinical outcome after microsurgical management of MCA aneurysms.

Our microsurgical cases included 20 patients presenting with SAH and good clinical condition, Hunt \& Hess score 1 and 2 in 60\%. At discharge, 16 $(80 \%)$ had good GOS and $4(20 \%)$ patients had poor GOS. After endovascular management of MCA aneurysms, all the 18 cases had favorable outcome (GOS grade $5 \& 4$ ) which remained the same at the last follow-up.

This can be, at least, partially explained by the fact that microsurgical cases were not selected cases. The microsurgical cases included all cases even those presenting in morbid clinical condition (Hunt \& Hess 4 or 5) and cases with large ICH. While, the endovascular cases were carefully selected, excluding cases in morbid clinical condition and cases with large ICH.

Microsurgical treatment of MCA aneurysms required no extra-resources than those available in neurosurgical departments with low cost of procedures, but the lack of resources to afford the required coils for dense backing of the aneurysms accounted largely to this high rate of incomplete 
obliteration after endovascular treatment. The literature up till now lacks a really randomized controlled trial that compares coiling to clipping of MCA aneurysms [11].

Most available studies, including ours, had some limitations as small sample size, selfjudgment or imbalanced groups. This calls for caution when implementing the results of these studies. In the ISAT study, analysis of ruptured MCA aneurysm group showed no statistically significant difference between poor outcome rate in the coiling arm (162 MCA aneurysms) and the clipping arm (139 MCA aneurysms). Poor outcome rates were $28.4 \%$ and $28.1 \%$ respectively. Outcome results of studies comparing coiling versus clipping for MCA aneurysms are sometimes biased by institutional selection policy of treatment modality [17]

Surgical clipping has significant advantages when considering treatment options for MCA aneurysms in patients presenting with ruptured MCA aneurysms accompanied by a large intracerebral hematoma in whom open surgery combining aneurysm clipping and hematoma evacuation are critical for relief of intracranial pressure to improve patient outcome [19].

In this study, 8 patients presented with an intracerebral hematoma requiring an immediate evacuation with aneurysm clipping. Good outcomes can be obtained by clipping when patients are carefully selected. In our study, good outcome was achieved in $80 \%$ of the clipped patients with complete occlusion rate of $100 \%$ which were close to the results of other series in which good outcomes were reported in 70-80\% of MCA aneurysm patients who underwent clipping for ruptured patients while aneurysm occlusion rates were $90-95 \%$. In a series of 631 MCA aneurysms managed with a "clip first" policy, good patient functional outcome was achieved in $87 \%$ of ruptured aneurysms, with an overall occlusion rate of $98.3 \% \quad[\mathbf{3 , 5 , 1 8}]$

\section{Conclusion:}

Although MCA aneurysms can be managed adequately via microsurgery or endovascular treatment, microsurgery is still the gold standard way to manage such aneurysms as it allows simultaneous management of intracerebral hematoma and hydrocephalus, which frequently complicate rupture of MCA aneurysms. Microsurgery offers a relatively safe, simple, cheap and durable treatment for MCA aneurysms. Endovascular treatment of MCA aneurysms is much more expensive, more complex and less durable than microsurgery. Endovascular treatment still has limitations for management of many cases of MCA aneurysms especially in the presence of large intracerebral hematoma. The clinical status of the patient before treatment is the most important factor affecting clinical outcome after treatment of MCA aneurysms than the treatment modality.

\section{Declaration:}

The authors declare no conflict of interest or any financial support and confirm the approval of the submitted article by the concerned ethical committee.

\section{References}

1- MOLYNEUX A.J., BIRKS J., CLARKE A., SNEADE M. and KERR R.S.C.: The durability of endovascular coiling versus neurosurgical clipping of ruptured cerebral aneurysms: 18 year follow-up of the UK cohort of the International Subarachnoid Aneurysm Trial (ISAT). Lancet, 385: 691-7, 2015.

2- ORIGITANO T.C.: Current options in clipping versus coiling of intracranial aneurysms: to clip, to coil, to wait and watch. Neurosurg. Clin. N. Am., 19 (3): p. 469-76, 2008.

3- RODRÍGUEZ-HERNÁNDEZ A., SUGHRUE M.E., AKHAVAN S., HABDANK-KOLACZKOWSKI J. and LAWTON M.T.: Current management of middle cerebral artery aneurysms: Surgical results with a "clip first" policy. Neurosurgery, 72: 415-27, 2013.

4- KIM K.H., CHA K.C., KIM J.S. and HONG S.C.: Endovascular coiling of middle cerebral artery aneurysms as an alternative to surgical clipping. J. Clin. Neurosci., 20 (4): 520-2, 2013.

5- VANDIJK J.M.C., GROEN R.J.M., LAANTER M., JELTEMA J.R., MOOIJ J.J.A. and METZEMAEKERS J.D.M.: Surgical clipping as the preferred treatment for aneurysms of the middle cerebral artery. Acta. Neurochir (Wien), 153: 2111-7, 2011.

6- STURIALE C.L., BRINJIKJI W., MURAD M.H., CLOFT H.J., KALLMES D.F. and LANZINO G.: Endovascular treatment of distal anterior cerebral artery aneurysms: single center experience and a systematic review. Am. J. Neuroradiol., 34: 2317-20, 2013.

7- MOLYNEUX A., KERR R., STRATTON I., SANDERCOCK P., CLARKE M., SHRIMPTON J. and HOLMAN R.: International Subarachnoid Aneurysm Trial (ISAT) of neurosurgical clipping versus endovascular coiling in 2143 patients with ruptured intracranial aneurysms: A randomised trial. Lancet, 360: 1267-74, 2002.

8- MCDOUGALL C.G., SPETZLER R.F., ZABRAMSKI J.M., PARTOVI S., HILLS N.K. and NAKAJI P.: The barrow ruptured aneurysm trial. J. Neurosurg., 116: 13544, 2012.

9- SPETZLER R.F., MCDOUGALL C.G., ALBUQUERQUE F.C., ZABRAMSKI J.M., HILLS N.K. and PARTOVI S.: The barrow ruptured aneurysm trial: 3-year results. J. Neurosurg., 119: 146-57, 2013. 
10- BAKKER N.A., METZEMAEKERS J.D.M., GROEN RJM, MOOIJ J.J.A. and VAN DIJK J.M.: International subarachnoid aneurysm trial 2009: Endovascular coiling of ruptured intracranial aneurysms has no significant advantage over neurosurgical clipping. Neurosurgery, 66: 961-2, 2010.

11-ZAIDAT O.O.,CASTONGUAY A.C., TELEB M.S., ASIF K., GHEITH A., SOUTHWOOD C., POLLOCK G. and LYNCH J.R.: Middle cerebral artery aneurysm endovascular and surgical therapies: Comprehensive literature review and local experience. Neurosurg. Clin. N. Am., 25 (3): p. 455-69, 2014.

12- MORTIMER A.M., BRADLEY M.D., MEWS P., MOLYNEUX A.J. and RENOWDEN S.A.: Endovascular treatment of 300 consecutive middle cerebral artery aneurysms: Clinical and radiologic outcomes. AJNR. Am. J. Neuroradiol., 35 (4): p. 706-14, 2014.

13- PIEROT L., KLISCH J., COGNARD C., SZIKORA I., MINE B., KADZIOLKA K., SYCHRA V., GUBUCZ I., JANUEL A.C. and LUBICZ B: Endovascular WEB fow disruption in middle cerebral artery aneurysms: Preliminary feasibility, clinical, and anatomical results in a multicenter study. Neurosurgery, 73 (1): p. 27-34, 2013.

14- MORGAN M.K., MAHATTANAKUL W., DAVIDSON A. and REID J.: Outcome for middle cerebral artery aneurysm surgery. Neurosurgery, 67 (3): p. 755-61, 2010.
15- TAWK R.G., PANDEY A., LEVY E., LIEBMAN K., ROSENWASSERR, HOPKINS L.N. and EROLVEZNEDAROGLU E.: Coiling of ruptured aneurysms followed by evacuation of hematoma. World Neurosurg, 74 (6): p. 626-31, 2010.

16- JIN S.C., KWON O.K., OH C.W., BANG J.S., HWANG G., PARK N.M., JUNG E.A., HAN M.H.,KANG H.S and PARK H.: Simple coiling using single or multiple catheters without balloons or stents in middle cerebral artery bifurcation aneurysms. Neuroradiology, 55 (3): p. 321-6, 2013.

17- MOLYNEUX A.J., KERR R.S.C., YU L-M., CLARKE M., SNEADE M., YARNOLD J.A. and SANDERCOCK P.: International Subarachnoid Aneurysm Trial (ISAT) of neurosurgical clipping versus endovascular coiling in 2143 patients with ruptured intracranial aneurysms: A randomized comparison of effects on survival, dependency, seizures, rebleeding, subgroups, and aneurysm occlusion. Lancet, 366: 809-17, 2005.

18- DIAZ O.M., RANGEL-CASTILLA L., BARBER S., MAYO R.C., KLUCZNIK R. and ZHANG Y.J.: Middle cerebral artery aneurysms: A single-center series comparing endovascular and surgical treatment. World Neurosurg., 81: 322-9, 2014.

19- YANG W. and HUANG J.: Treatment of middle cerebral artery (MCA) aneurysms: A review of the literature. Chinese Neurosurgical Journal, 1: 1, 2015.

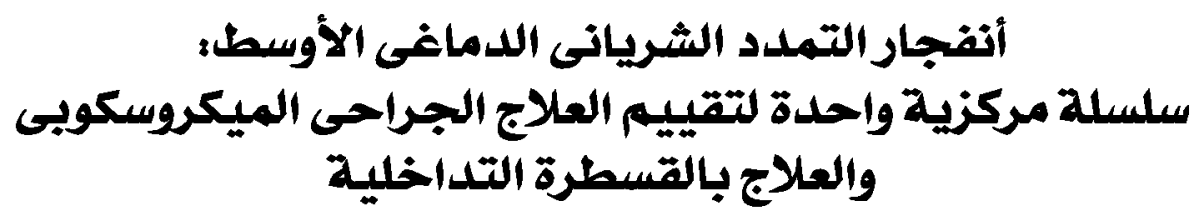

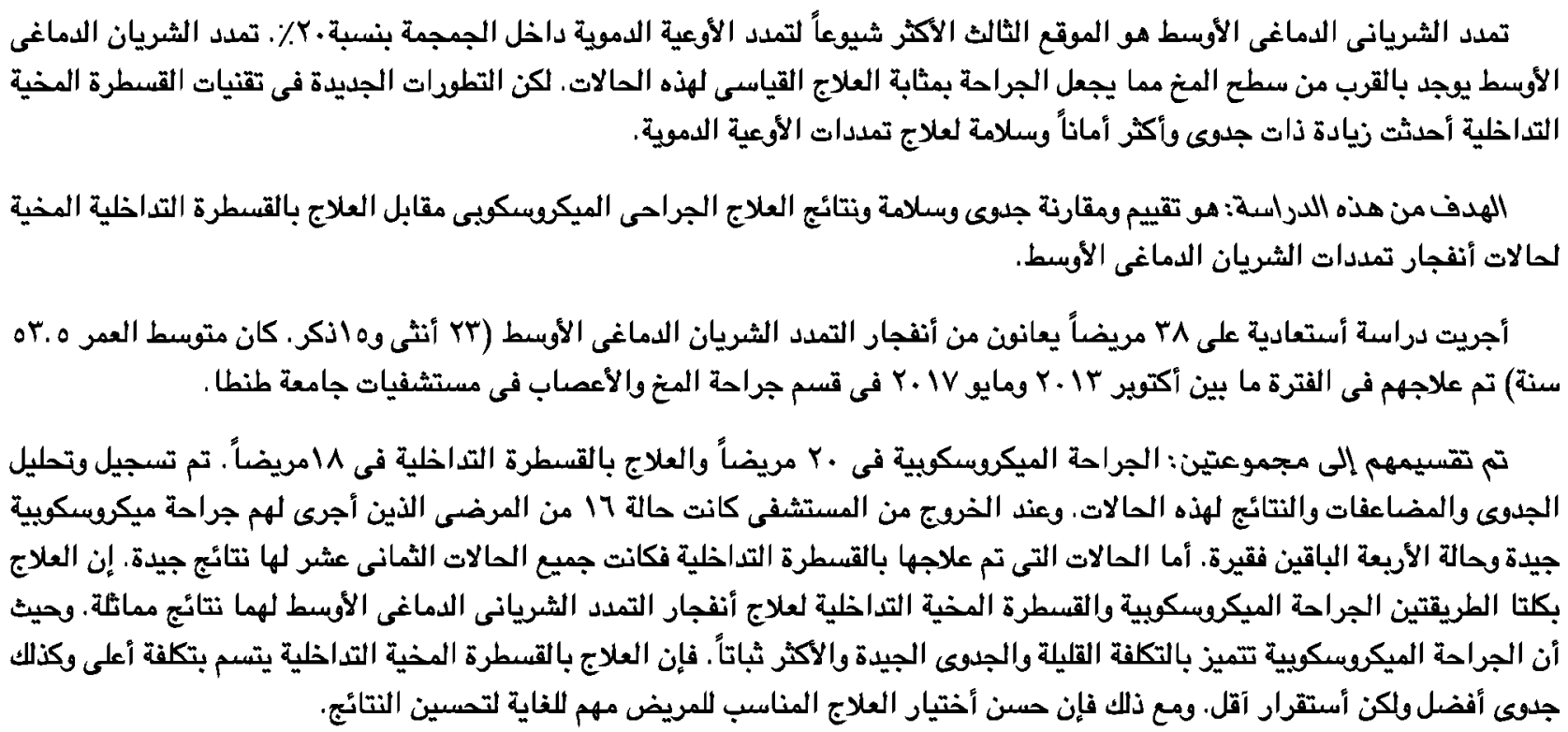

